\title{
Raman Lidar for Meteorological Observations, RALMO - Part 2: Validation of water vapor measurements
}

\author{
E. Brocard ${ }^{1}$, R. Philipona ${ }^{1}$, A. Haefele ${ }^{1}$, G. Romanens ${ }^{1}$, A. Mueller ${ }^{1}$, D. Ruffieux ${ }^{1}$, V. Simeonov ${ }^{2}$, and B. Calpini ${ }^{1}$ \\ ${ }^{1}$ Federal Office of Meteorology and Climatology MeteoSwiss, Payerne, Switzerland \\ ${ }^{2}$ Laboratory of Environmental Fluid Mechanics and Hydrology, Lausanne, Switzerland
}

Correspondence to: E. Brocard (emmanuel.brocard@meteoswiss.ch)

Received: 2 July 2012 - Published in Atmos. Meas. Tech. Discuss.: 20 September 2012

Revised: 15 March 2013 - Accepted: 26 March 2013 - Published: 22 May 2013

\begin{abstract}
The Raman Lidar for Meteorological Observations (RALMO) was installed at the MeteoSwiss Regional Center of Payerne, Switzerland, in summer 2008. One of its aims is to provide continuous vertical profiles of tropospheric water vapor during day and night at a high temporal resolution. Twelve months (October 2009-September 2010) of lidar data are analyzed. During this period of time, the lidar produced 9086 profiles, representing $52.6 \%$ of the time (this figure reached $63.2 \%$ for the first 6 months of 2011). Under cloud-free conditions, half of the profiles reached more than $8610 \mathrm{~m}$ above ground level at night, and $4050 \mathrm{~m}$ during the day. In order to validate the capabilities of the instrument, the year of lidar data was compared to the collocated radiosondes. On average, lidar water vapor mixing ratio was found to be within 5 to $10 \%$ of radiosonde values up to $8 \mathrm{~km}$ at night, and within $3 \%$ up to $3 \mathrm{~km}$ during the day. Relative humidity results show an agreement within 2 and $5 \%$ for day and night, respectively. An integrated water vapor comparison also shows a good correlation with both radiosondes and GPS measurements: the lidar had a $4.2 \%$ dry bias compared to radiosondes and a $5.3 \%$ wet bias compared to GPS. These results validate the performance of the lidar and the humidity profiles with a $30 \mathrm{~min}$ time resolution.
\end{abstract}

\section{Introduction}

Water vapor is a key component of the Earth's atmosphere. It is the strongest greenhouse gas, and changes in its concentration have many implications in the climate and radiative system (IPCC, 2007). Water vapor density is highly variable in time and space. Knowledge of the atmospheric humidity profile is of primary importance for applications such as numerical weather prediction models but also for integration with other methods of observation such as surface rain gauge, weather radar, and remote sensing of clouds.

A wide range of ground-based in situ and remote sensing techniques is available for water vapor measurements in the troposphere and the middle atmosphere. For a thorough review of the different methods the reader is referred to Kämpfer (2013) and references therein. Lidar is one of the only techniques that has the capacity to resolve both the temporal and the spatial variability of water vapor and is hence of greatest interest for the use in meteorological applications. A discussion of the state of the art of water vapor profiling with lidar is given in the companion paper Dinoev et al. (2013). The lidar technique has been compared to other techniques (Wirth et al., 2009; Bleisch et al., 2011; Vogelmann et al., 2011; Leblanc et al., 2011) and shows good performance. Recent advances in lidar research allowed the development of the first automatic day- and night-time water vapor lidars dedicated to the use in operational meteorology (Goldsmith et al., 1998; Engelbart et al., 2006; Apituley et al., 2009; Dinoev et al., 2013).

At the MeteoSwiss Regional Center of Payerne, atmospheric water vapor profiles are measured twice daily with radiosondes. Since summer 2008, a Raman lidar has been installed and tested on site. The aim of this instrument is to continuously provide tropospheric water vapor profiles during day and night at a $30 \mathrm{~min}$ repetition rate, primarily for the operational needs of MeteoSwiss. Figure 1 illustrates how the lidar bridges the gap between radiosonde profiles. The evolution of humid or dry layers in time and altitude can be followed in near real time. This provides 


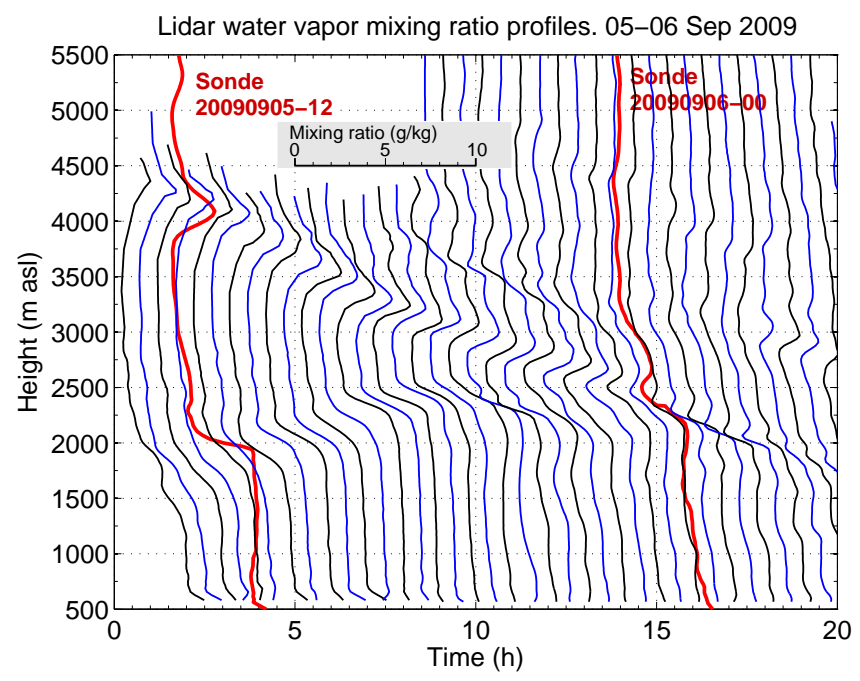

Fig. 1. Lidar water vapor mixing ratio profiles time series. Lidar profiles are plotted in blue and black with a $30 \mathrm{~min}$ time resolution. Each successive profile is shifted to the right by $30 \mathrm{~min}$ on the $\mathrm{x}$-axis. The mixing ratio scale is shown in the plot window. Collocated radiosonde profiles are super-imposed in red. This plot illustrates the lidar capability of filling the information gap between radiosonde profiles. The lidar provides a profile every $30 \mathrm{~min}$, whereas radiosondes are available only twice a day.

valuable information on the state of the atmosphere at a high temporal resolution.

The comparison presented in this paper aims at proving the quality and consistency of lidar profiles. It will provide an overview of the lidar's performance during one year of operation, and will be used as a comparison benchmark for future analyses. The validation of lidar profiles is the first step towards having an operational instrument with $30 \mathrm{~min}$ time resolution available for assimilation by state of the art weather prediction models. The comparison between lidar and radiosonde shown in this paper is based on one profile intercomparison every $12 \mathrm{~h}$ at best $(771$ radiosonde have been launched during the year under study). The continuous performance of the lidar (every half-hour) is not assessed. It has to be noted that the dataset is dependent on the technical specifications and the weather conditions. This paper is structured as follows: Sect. 2 briefly presents the lidar used in this study. Section 3 details the water vapor retrieval performed with the lidar. Section 4 describes the lidar dataset, in particular the profiles characteristics and the system stability. It also describes the radiosonde dataset. Section 5 presents the comparison results in terms of water vapor profiles and integrated water vapor (IWV). Section 6 discusses important points concerning this comparison, in particular the observed biases. Section 7 presents the conclusions.

\section{Instrument description}

The Raman Lidar for Meteorological Observations (RALMO) is a custom-designed instrument, operated at MeteoSwiss Payerne since August 2008. It has been developed by the Swiss Federal Institute of Technology (EPFL) for the needs of MeteoSwiss (Dinoev, 2009). While other lidar groups have successfully taken the approach of using large integration time during night-time conditions (thus avoiding any daytime sunlight interferences) in order to produce profiles up to the upper troposphere-lower stratosphere region (Leblanc et al., 2008, 2012), in Payerne our aim is to make continuous measurements of tropospheric water vapor at a high temporal resolution during both day and night. The lidar system uses a trippled Nd:YAG laser that emits laser pulses ( $<8 \mathrm{~ns}$ duration) at a repetition rate of $30 \mathrm{~Hz}$. The typical energy per pulse at the wavelength of $354.7 \mathrm{~nm}$ is around $300 \mathrm{~mJ}$, revealing an average power of approximately $9 \mathrm{~W}$. Before being emitted in the atmosphere the beam is expanded to a diameter of $140 \mathrm{~mm}$. This ensures an eye-safe laser beam and reduces beam divergence to $0.1 \mathrm{mrad}$. Four telescopes with 30-centimeter parabolic mirrors are arranged symmetrically around the vertical outgoing beam to receive the backscattered photons. The telescope system has a total aperture equivalent to a telescope of $60 \mathrm{~cm}$ diameter and a field of view of $0.2 \mathrm{mrad}$. The narrow field of view together with narrowband receiver allows daytime operation. Optical fibers connect the telescope mirrors with a grating polychromator used to isolate the rotational-vibrational Raman signals of nitrogen and water vapor (wavelengths of 386.7 and $407.5 \mathrm{~nm}$, respectively). The optical signals are detected by photomultipliers and acquired by a transient recorder. A detailed description of the instrument is available in the companion paper.

\section{Water vapor retrieval}

A water vapor mixing ratio profile, $q(z)$, is retrieved from the nitrogen and water vapor rotational-vibrational Raman signals, $s_{\mathrm{N}_{2}}(z)$ and $s_{\mathrm{H}_{2} \mathrm{O}}(z)$, as follows:

$q(z)=C \cdot\left(\frac{s_{\mathrm{H}_{2} \mathrm{O}}(z)-b_{\mathrm{H}_{2} \mathrm{O}}}{s_{\mathrm{N}_{2}}(z)-b_{\mathrm{N}_{2}}}\right) \cdot \frac{\exp \left[-\tau_{\mathrm{N}_{2}}(z)\right]}{\exp \left[-\tau_{\mathrm{H}_{2} \mathrm{O}}(z)\right]}$

$\tau_{\mathrm{N}_{2}}(z)$ and $\tau_{\mathrm{H}_{2} \mathrm{O}}(z)$ are the opacities due to molecular extinction between the surface and the altitude $z$ at 386.7 and $407.5 \mathrm{~nm}$, respectively. The estimation of molecular extinction is based on the US Standard Atmosphere. For normal conditions at Payerne the effect of differential extinction due to aerosols is small and is neglected (Dinoev et al., 2013). The background signals $b_{\mathrm{H}_{2} \mathrm{O}}$ and $b_{\mathrm{N}_{2}}$ are determined from the corresponding measured signals above $40 \mathrm{~km}$. The statistical error of the water vapor profile is calculated from the variance of the uncorrected signals using Poisson statistics. The calibration constant $C$ is calculated from 
Table 1. Yearly time percental of the different flags allocated by the system for the period 1 October 2009 to 30 September 2010.

\begin{tabular}{lcc}
\hline Flag & Lidar status & Time percental (\%) \\
\hline Normal operation & On & 52.6 \\
Maintenance and & Off & 25.7 \\
technical problems & & \\
Rain & Standby & 16.2 \\
Low clouds & Standby & 5.5 \\
\hline
\end{tabular}

intercomparisons with collocated radiosoundings equipped with the SnowWhite hygrometer. SnowWhite is a frost/dew point hygrometer for the troposphere and lower stratosphere (Fujiwara et al., 2003; Vömel et al., 2003). $C$ is chosen using a linear least-square method, so that the sum of the square differences between lidar mixing ratio profile $q(z)$ and Snow White radiosonde mixing ratio profile, $q_{\mathrm{S}}(z)$, is minimal. Only the first $6 \mathrm{~km}$ of the profiles are considered for the fitting. It is important to note that the radiosondes used for lidar calibration (SnowWhite) are different from the radiosondes used for the validation (operational SRS-400 with capacitive Rotronic HC2 sensor, see Sect. 4.2).

Each lidar raw data file contains an integration over 1800 shots, which corresponds to a one-minute integration time. For the inversion, an average over 30 raw data files is used, thus corresponding to a total of 54000 shots and a $30 \mathrm{~min}$ integration time. The raw signals are desaturated and offset corrected. In the case of the water vapor Raman signal the analog and photon counting channels are combined (glued) to achieve best linearity under daytime conditions. Furthermore, a gliding average smoothing using a rectangular filter has been applied to the raw signals in order to reduce the statistical uncertainty. The vertical resolution, defined as the width of the vertical smoothing window, is increased with altitude from 30 to maximum $600 \mathrm{~m}$ such that the statistical uncertainty is smaller than $10 \%$. This results in profile to profile variations in terms of vertical resolution according to atmospheric conditions. More details of the water vapor retrieval is available in the companion paper.

\section{Datasets}

\subsection{Lidar dataset}

\subsubsection{Profiles availability and continuity}

A one-year dataset has been selected for the comparison. The chosen period extends from 1 October 2009 to 30 September 2010 . During this $1 \mathrm{yr}$ period, the lidar produced profiles $52.6 \%$ of the time, which represents a total of 9086 profiles. During the remaining time, the lidar was either in standby mode, due to external factors such as rain or low clouds, or was turned off due to maintenance or technical problems.

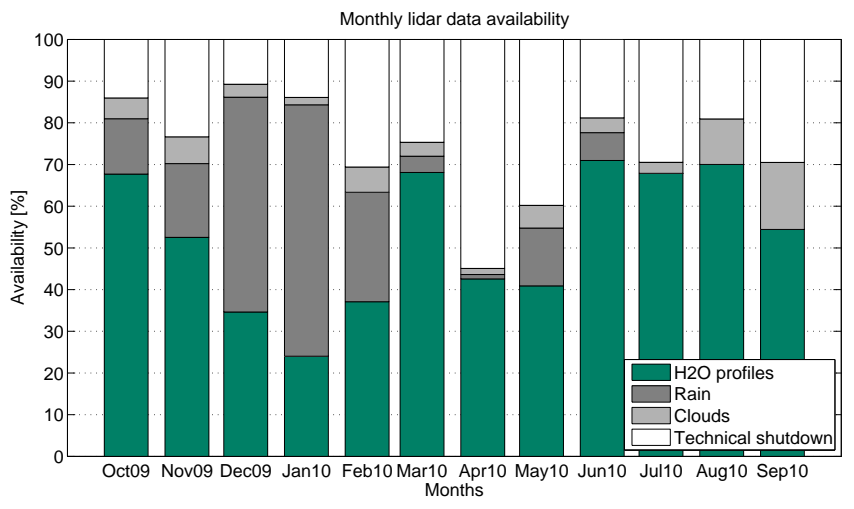

Fig. 2. Lidar data availability for the period 1 October 2009 to 30 September 2010. Green bars represent the percentage of time when the lidar is producing humidity profiles. Grey bars represent the percentage of time when the lidar is in standby mode due to either rain or low clouds. White bars represent the percentage of time when the lidar is off due to maintenance or technical problems.

Table 1 summarizes the percentage of time allocated to the different instrumental flags. It should be noted that the figures in Table 1 are housekeeping parameters, which may include delays between on and off times. For example, the $16.2 \%$ of time flagged as "rain" includes not only the time when precipitation occurs, but also includes the transition period between end of rain and system start-up. This time delay may reach typically $1 \mathrm{~h}$ and include pre-warming laser operation before standard lidar observations are performed. An additional 90 min standby time was added between end of precipitation and beginning of system start-up in order to avoid frequent start-up/shutdown procedures in case of intermittent rain conditions. During this time, the system is operational although not retrieving profiles. Therefore, the $52.6 \%$ of "normal operation" is the time when the lidar produced profiles. The time percental when the instrument is actually operational is larger.

It is to be noted that we acquired more experience operating the system, which results in higher percentage of operational time. For the first 6 months of 2011, the lidar produced profiles $63.2 \%$ of the time. Figure 2 graphically illustrates profile availability during the comparison period. Since lidar operation is weather-dependent, data availability is highly variable versus time, thus a seasonal cycle can be seen: more precipitation and low clouds in winter, more clear-sky situations in summer. During suitable weather conditions (no rain, no low clouds), the lidar can run for several days up to 2-3 weeks uninterrupted. Regular maintenance tasks include laser flash lamps replacement or manual high-voltage adjustment of the laser. The corresponding shutdown time is of the order of 1-2 working days per month. Telescope re-alignment is needed only for changes related to the laser source. Re-calibration has to be performed only for changes affecting the efficiency of detection, 
e.g. changes in the optics, the photomultiplier or the polychromator. The remaining shutdown time is due to technical problems (e.g. cooling or air conditioning units, laser source repair or maintenance), which leaves room for further improvements. It should also be noted that there are neither automated alert systems nor personnel on duty operating the system outside regular working hours. This delays the start of repair work in case of a technical problem.

\subsubsection{System stability}

During the selected period, no major changes took place in the instrument configuration and hardware. The lidar calibration coefficient was recalculated at the beginning of October 2009, using one SnowWhite radiosonde profile, and was left unchanged during the whole year. The system remained rather stable, as illustrated in Fig. 3, which shows the temporal evolution of the difference between radiosondes (operational SRS-400 with Rotronic sensor) and lidar at different altitude levels. In this plot, data that are more than 3 standard deviations away from the mean have been removed in order to avoid having obvious outliers impacting the trend (this concerns just a few points at each level). After the recalibration in October 2009, the lidar shows a high level of stability. Over an eight-month period from November 2009 to June 2010, the mean monthly bias is $+0.12 \pm 0.17 \%$ month $^{-1}$ at $1 \mathrm{~km}$ a.s.l. $(+0.51 \pm 0.36 \%$ at $2 \mathrm{~km}$ a.s.1.). From July to September 2010, however, a trend of $-4.4 \pm 0.76 \%$ month $^{-1}$ is observed $(-5.0 \pm 1.2 \%)$.

Recent comparisons in 2011 between lidar and SnowWhite radiosondes (not shown) confirm the above results. This drift is due to uneven aging of water vapor and nitrogen photomultipliers caused by the intensive summer solar background. It is noted that a system for automatically correcting the ageing effect is currently under consideration.

For some profiles, lidar and radiosonde measurements differ substantially at a given height, hence the outliers in Fig. 3. On a point-by-point comparison, having outlying values may happen. This is due to a combination of several factors, such as problems of space or time collocation, different measurement times (see Sect. 5), or problems related to specific limitations of the radiosonde sensor (see Sect. 6.2).

From these results, we conclude that the system can remain stable over long period of time, on the order of several months. However, a check of the calibration once a month has been introduced to monitor stability and to correct for possible drifts.

\subsubsection{Altitude reached by the profiles}

The altitude of the highest point in each lidar profile has been extracted. The distribution is shown in Fig. 4. The corresponding statistics are reported in Table 2. The highest point is defined as the highest point in the profile with a statistical error below $10 \%$ (see Sect. 2). In Table 2, two types of
Table 2. Mean and median of the highest point (meters above ground level) in lidar profiles for day and night. Integration time: $30 \mathrm{~min}$. Day, night, and clear sky are defined in Sect. 4.4.

\begin{tabular}{lcc}
\hline & $\begin{array}{c}\text { Clear-sky } \\
\text { (m a.g.l.) }\end{array}$ & $\begin{array}{c}\text { All data } \\
\text { (m a.g.l.) }\end{array}$ \\
\hline Mean night & 8318 & 6879 \\
Mean day & 4047 & 3545 \\
Median night & 8610 & 7500 \\
Median day & 4050 & 3480 \\
\hline
\end{tabular}

information are shown. First, results for all data are given. They characterize the lidar performance for all profiles during the 12-month period. There, the highest altitude reached by the profiles are strongly limited by clouds. On average, the highest point was at $6879 \mathrm{~m}$ above ground level (a.g.l.) during night-time conditions and at $3545 \mathrm{~m}$ a.g.l. during daytime. Regarding median values, half of the profiles reached a height of $7500 \mathrm{~m}$ a.g.l. at night and $3480 \mathrm{~m}$ during the day. Second, results for cloud-free data are given. These results are not affected by clouds; they therefore reflect the intrinsic performance of the instrument's optics during the time period under study. For a given integration time, the altitude reached by the profiles are limited only by instrumental factors, such as laser source intensity and laser beam divergence, telescope alignment, telescope's active surface and optics quality, light filtering system quality, and/or solar background noise rejection. During cloud-free periods, a profile reached on average $8318 \mathrm{ma}$ a.g.l. during night-time conditions, and $4047 \mathrm{~m}$ a.g.l. during daytime. Half of the profiles reached a height of $8610 \mathrm{~m}$ a.g.l. at night and $4050 \mathrm{~m}$ during the day.

These results attest that the lidar has the capability of retrieving humidity profiles at night over most of the troposphere with an integration time as short as $30 \mathrm{~min}$. Higher heights could yet be achieved with a longer integration time. During the day, profiles reach a lower altitude than at night, as expected. This is due to the high solar background level and the consequently reduced signal-to-noise ratio at higher altitudes. Despite these daytime conditions, humidity profiles cover a large part of the tropospheric water vapor content. The diurnal distribution of highest points agrees qualitatively well with those derived from the ARM Raman lidar (e.g. Ferrare et al., 2006). It is noted that additional profile height limiting conditions may include scattered clouds, full moon nights, low laser power, or cirrus clouds or aerosol layers due to the clear-sky selection algorithm (see Sect. 4.4).

\subsection{Radiosonde dataset}

Radiosonde data were taken from the operational radiosonde dataset from Payerne. The station is part of the GCOS Reference Upper Air Network (GRUAN) (Seidel et al., 2009). Furthermore, the station has recently been appointed as official test-bed site for the World Meteorological Organization's 


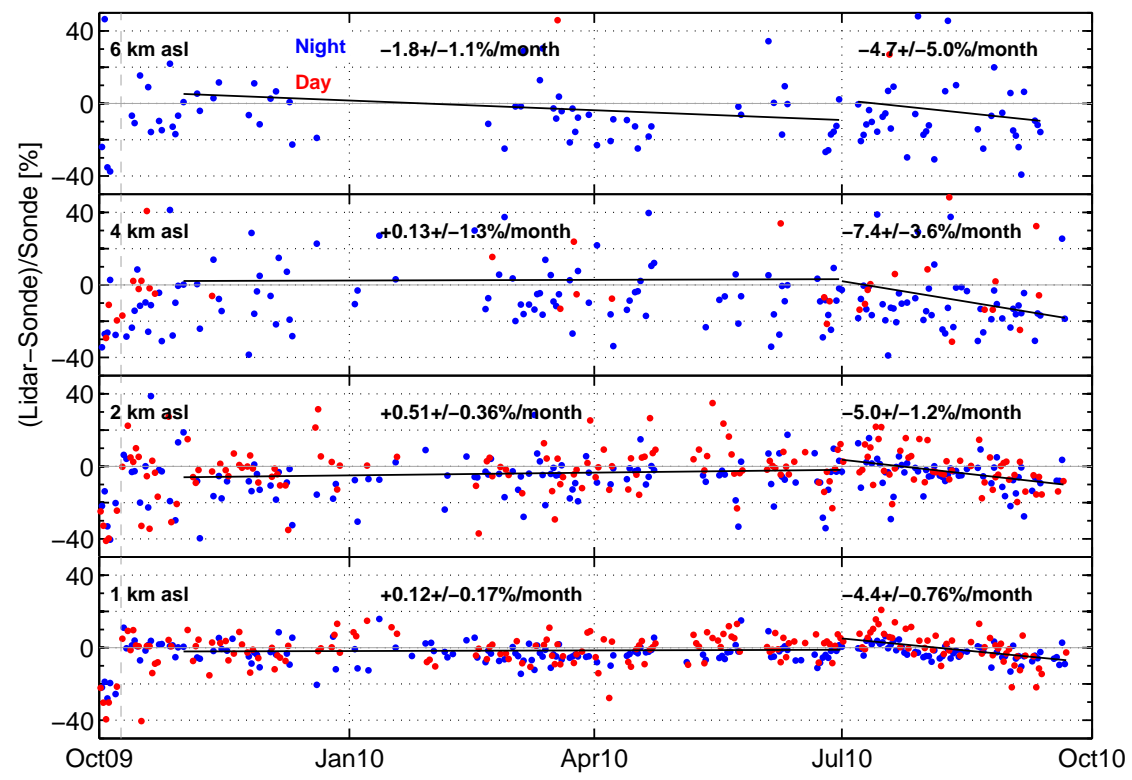

Fig. 3. Temporal evolution of water vapor mixing ratio differences between lidar and sonde at different altitude levels (from top to bottom: 6 , 4, 2 and $1 \mathrm{~km}$ a.s.1.). Trends are shown for two time periods: from November 2009 to June 2010, the system remained relatively stable, and from July to September 2010, a drift is visible. The drift is mainly due to a photodetector sensitivity decrease. A recalibration was performed beginning of October 2009.

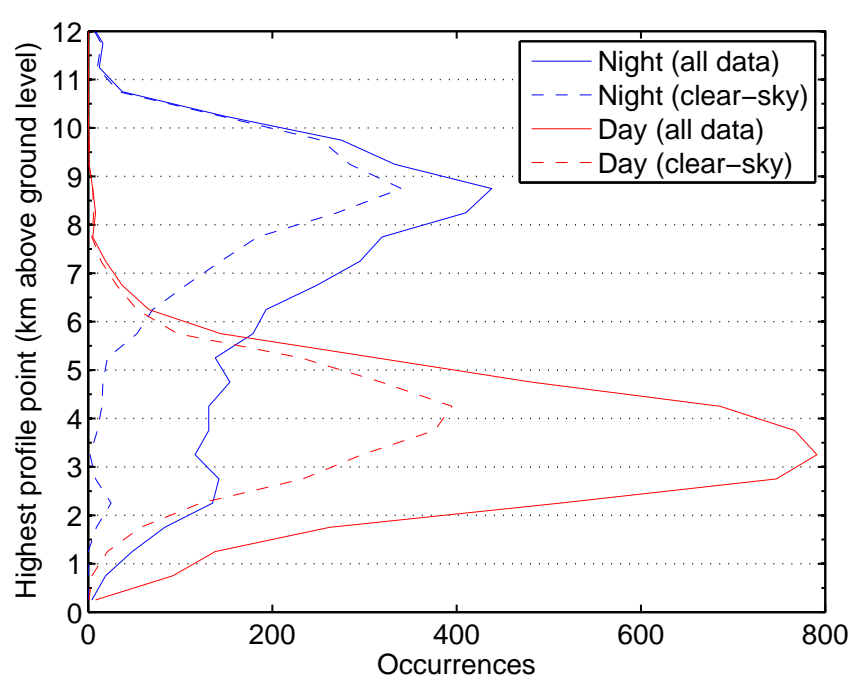

Fig. 4. Distribution of highest point in lidar profiles for clear-sky (dotted) and all-sky (solid) during night (blue) and day (red). Period: 1 October 2009 to 30 September 2010. Number of profiles: 9086.

Commission for Instruments and Methods of Observations (WMO-CIMO).

The radiosonde type used for this study is the SRS-400, manufactured by Meteolabor AG. It is equipped with a capacitive Rotronic HC2 humidity sensor (Philipona et al., 2009). Rotronic sensors are thoroughly tested and calibrated by the manufacturer before being sold. In Payerne, a groundcheck is carried out by a comparison with a reference mea- surement just before launch. Tests performed in Payerne on dual flights (two HC2 sensors) show excellent consistency between sensors (not shown). A new version of this sonde (C34 digital radiosonde including Global Positioning System [GPS]) using the same sensors has recently participated in the international intercomparison 2010 of high-quality radiosondes organized by the World Meteorological Organization (WMO) (Nash et al., 2011). During this intercomparison, the humidity sensor was found to measure values that were too large (wet bias) in integrated water vapor (IWV) compared to GPS measurements. The magnitude of this bias is of the order of $+5 \%$. In terms of relative humidity, the sensor was found to generally have a wet bias at tropospheric temperatures also of the order of $+5 \%$. Comparison flights using an HC2 sensor, a SnowWhite frost-point hygrometer, and a Vaisala RS92 radiosondes are regularly carried out at Payerne. The three sondes usually agree within a few percentage points up to about $8 \mathrm{~km}$ above sea level (Fig. 5). The radiosonde is launched routinely twice a day at 11:00 UTC and 23:00 UTC. Additional launches are made occasionally, for instance during measurement campaigns or other special events. For the year under study, a total of 771 operational profiles have been collected. The distance between the radiosonde launch site and the lidar is approximately $100 \mathrm{~m}$. To do the comparison, the lidar vertical grid is taken as reference. Each lidar vertical grid point is matched with the closest point in the radiosonde vertical grid. The radiosonde value is then taken as the average of all points within $50 \mathrm{~m}$ above and $50 \mathrm{~m}$ below that grid point. 


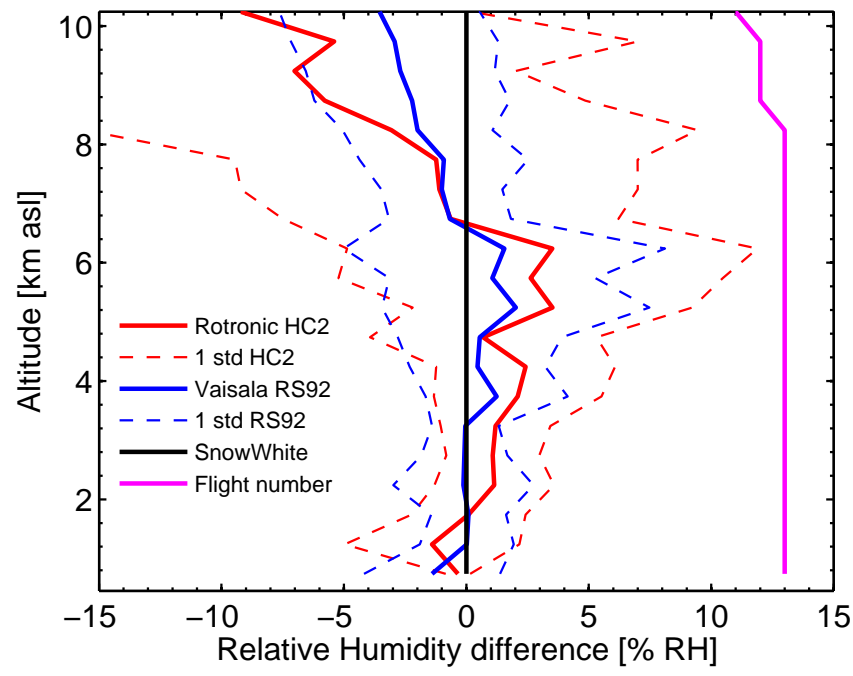

Fig. 5. Mean relative humidity difference between SnowWhite (black, reference), Rotronic HC2 (red) and Vaisala RS92 (blue) sondes. 1 standard deviation is shown (dashed lines). Results based on 13 comparison flights made at night in 2011.

\subsection{GPS and microwave radiometer datasets}

In Sect. 5.2, we compare integrated water vapor results from lidar and radiosondes to GPS and microwave radiometer measurements. Both the GPS and the microwave radiometer are located on the Payerne site (within $100 \mathrm{~m}$ of the lidar and radiosonde launch site). IWV calculations from GPS are based on World Meteorological Organization guidelines (de Haan et al., 2008; Eumetnet, 2009); the uncertainties are in the order of $1-2 \mathrm{~mm}$ in the range $10-40 \mathrm{~mm}$. IWV calculations from microwave radiometer are made with a HATPRO radiometer from Radiometer Physics GmbH (RPG, 2011); IWV uncertainties are in the order of $0.5-0.8 \mathrm{~mm}$ (Löhnert et al., 2011). The microwave radiometer is pointing vertically with a field of view of $3.5^{\circ}$ (HPBW) and an integration time of $1 \mathrm{~s}$. For comparison with the lidar, the IWV values are then averaged over $30 \mathrm{~min}$.

\subsection{Definitions}

In this paper, several situations are distinguished: day, night and clear-sky. Clear-sky situation is based on the APCADA algorithm (Duerr and Philipona, 2004), which estimates cloud fraction. This algorithm determines cloud fraction using longwave downward radiation and surface temperature and humidity measurements with a $10 \mathrm{~min}$ resolution. The range goes from 0 octa (clear-sky) to 8 octa (overcast). A lidar profile is categorized as clear-sky if the mean APCADA factor during the $30 \mathrm{~min}$ of lidar integration time is less than or equal to 2 octa (2/8th of the sky covered with clouds). According to internal tests (not shown), this assumption ensures that clear-sky situations are properly discriminated. In a few cases, however, isolated clouds or cirrus clouds might not be
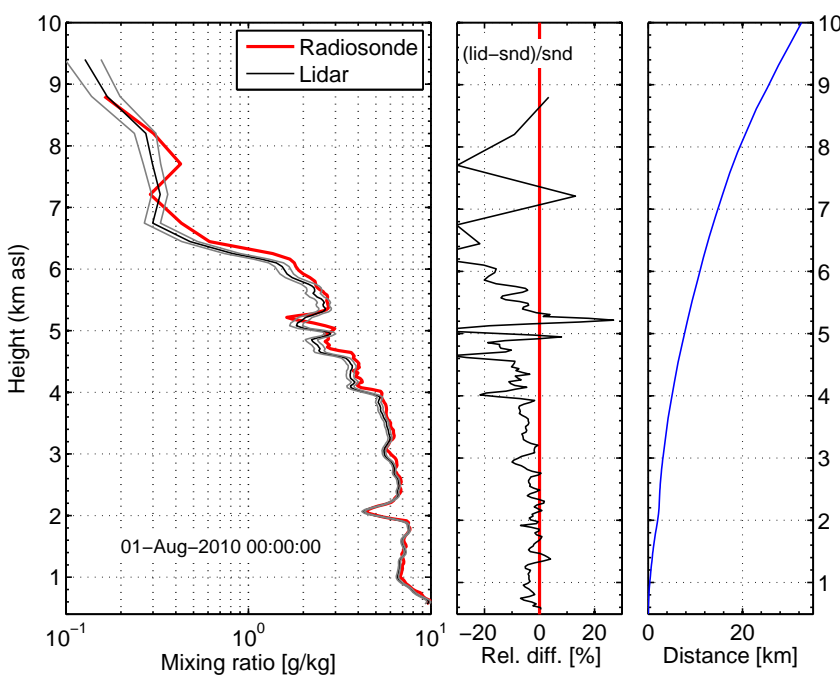

Fig. 6. Example of night-time water vapor mixing ratio profiles from lidar and radiosonde (left panel). The radiosonde profile (solid red) is taken as working reference. Mixing ratio relative difference between lidar and radiosonde (middle panel). Profile of horizontal distance between launch site and radiosonde (right panel).

detected and affect lidar profiles. Using APCADA also ensures that the whole sky is clear, and not only the fraction above the lidar.

A profile is defined as a night profile if the solar zenith angle is greater than $95^{\circ}$, and it is defined as a day profile if the solar zenith angle is smaller than $95^{\circ}$. This is a valid assumption for more than $95 \%$ of the flights that are in the analyzed dataset. For the $5 \%$ remaining (i.e. launches at 06:00 and 18:00 UTC), the 95 degree sun zenith angle is taken as the filter between night and day. At 95 degree zenith angle the lowest part of the atmosphere illuminated by the Sun is at approximately $24 \mathrm{~km}$, i.e. below the background reference height of the lidar. However, there might still be some light reaching the lidar through scattering.

\section{Comparison with SRS-400 radiosondes}

\subsection{Water vapor profiles}

During the period from 1 October 2009 to 30 September 2010, a total of 168 matching clear-sky profiles were collected, 97 night profiles and 71 day profiles. An example of water vapor mixing ratio measured by lidar and radiosonde is presented in Fig. 6. The agreement between radiosonde and lidar is generally very good. Small-scale vertical structures, visible in radiosonde profiles, are well seen by the lidar. In the upper part of the profile, however, discrepancies are more likely to be observed. Indeed, the lidar measures along a vertical axis above the instrument, whereas the radiosonde drifts with the wind and therefore does not sample the same air parcel as the lidar. This would happen, for example, in 
Fig. 1, where a wet air layer moves down rapidly. During the year under study, at an altitude of $8 \mathrm{~km}$, which corresponds to a typically-reached height during night, the mean horizontal distance to the launch site was approximately $22 \mathrm{~km}$ (maximum distance was $66 \mathrm{~km}$ ). The same air mass is sampled at a slightly different altitude (in the order of tens of meters) related to the horizontal distance mismatch. In the example given in Fig. 6, this shift is visible, for example at around $5 \mathrm{~km}$ altitude, where a thin, drier layer is seen at a slightly different altitude. At this height, the radiosonde sampled an air parcel $8.4 \mathrm{~km}$ horizontally away from the station. The influence of different temporal and spatial matching and its impact on the system has been previously discussed in the literature (e.g. Sussmann et al., 2009; Schneider et al., 2010; Vogelmann et al., 2011; Dionisi et al., 2010).

For the comparison, each radiosonde launch is associated with its time-collocated lidar profile. For example, the night radiosonde is launched at 23:00 UTC. It samples the troposphere roughly between 23:00 and 23:30 (the ascent rate is about $5 \mathrm{~m} \mathrm{~s}^{-1}$ ). The time-collocated lidar profile is the one produced at 23:30, which results from the signal integrated from 23:00 to 23:30. This ensures that a similar time window is used. If no lidar profiles are produced, no comparison is made for this point. The same applies for the day launch at 11:00 UTC.

The average one-year lidar and radiosonde water vapor night profiles are shown in Fig. 7. Water vapor is expressed in units of mixing ratio and in units of relative humidity with respect to liquid water. For the conversion of lidar water vapor mixing ratio profiles into relative humidity profiles, the temperature and pressure profiles from the collocated radiosondes are used, as the lidar temperature profiling capability is not yet fully operational. In the troposphere, the sonde's altitude error is on the order of meters, and is neglected when calculating relative humidity.

During night, the difference between lidar and sonde shows negative values of 5 to $10 \%$ up to $7.5 \mathrm{~km}$. In terms of relative humidity, it represents a difference of less than $5 \%$ of relative humidity. At higher altitude, the difference becomes positive. However, the upper part of the profiles is more noisy. This is explained by two factors. First, the lidar signal-to-noise ratio decreases with height, hence more challenging conditions for the lidar to retrieve humidity values. Second, the number of lidar profiles available to calculate the mean decreases with height, hence less points for the mean value. In the upper part of the profile, we observe a positive difference between lidar and radiosonde. This would need to be further investigated.

During the day, both sets of profiles agree very well up to about $4 \mathrm{~km}$ altitude. The average one-year water vapor day profiles are shown in Fig. 8. Although the altitude reached is lower than at night, the agreement between lidar and sonde is very good from the ground level to about $4 \mathrm{~km}$ above ground. The lidar mixing ratio relative difference stays within 2 to $3 \%$ of the radiosonde value, or within $2 \%$ relative humid-
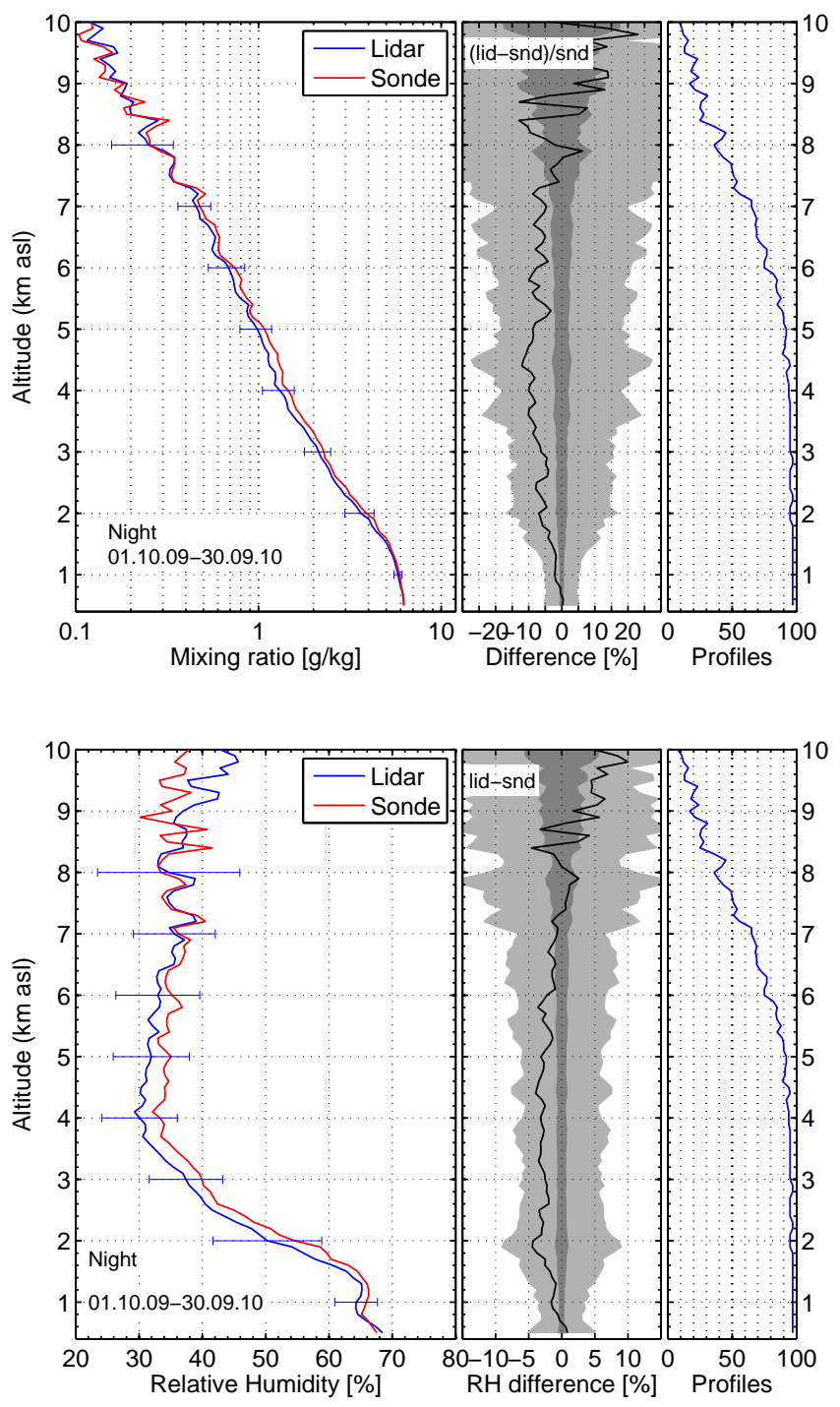

Fig. 7. Top: mean water vapor mixing ratio (left) and mean bias profile (middle) during night. Bottom: mean relative humidity with respect to water (left) and bias profile (middle) during night. Right: number of available profiles $n$. Middle panels: mean value (solid black), standard deviation $\sigma$ (light grey), error of the mean value $(\sigma / \sqrt{n}$, dark grey). Only clear-sky days are considered.

ity up to $3 \mathrm{~km}$ altitude. These values are mostly within the uncertainty margin of the comparison. Past 3.5 to $4 \mathrm{~km}$, the lidar shows a more noisy signal and a wet bias. It is due to the diminishing number of profiles accounting for the mean calculation, a poor lidar signal-to-noise ratio (here mainly due to daytime sunlight interferences), and background effects.

Figure 9 shows the water vapor mixing ratio correlation between lidar and radiosonde. At night, the correlation is very high, with a correlation coefficient of more than 0.98 . During the day, the correlation is also very high with a correlation coefficient of more than 0.96 . However, the lidar slightly overestimates the mixing ratio values above 

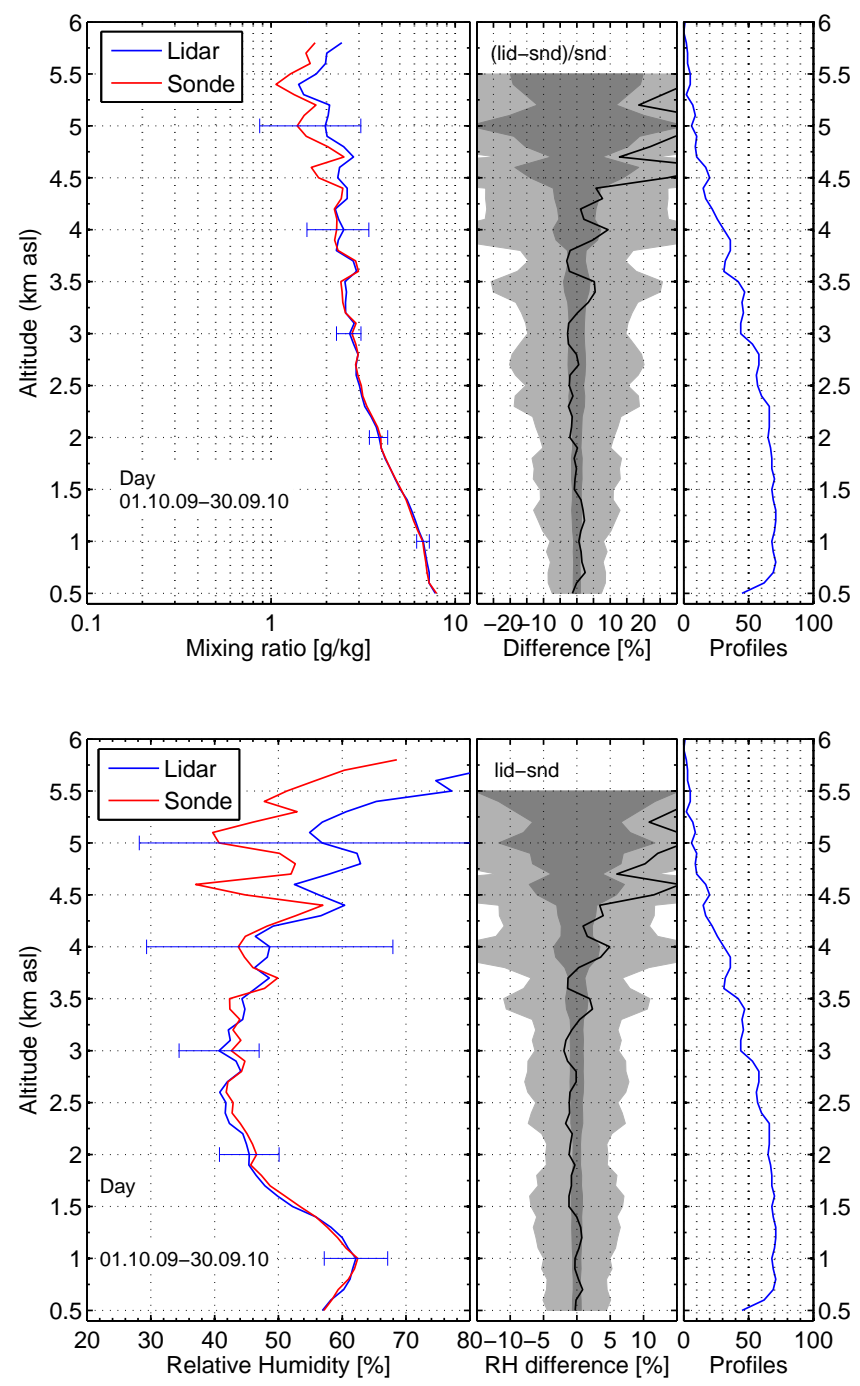

Fig. 8. Top: mean water vapor mixing ratio (left) and mean bias profile (middle) during day. Bottom: mean relative humidity with respect to water (left) and bias profile (middle) during day. Right panels: number of available profiles $n$. Middle panels: mean value (solid black), standard deviation $\sigma$ (light grey), error of the mean value $(\sigma / \sqrt{n}$, dark grey). Only clear-sky days are considered.

$10 \mathrm{~g} \mathrm{~kg}^{-1}$. These values are usually found in low-altitude humid layers during warm summer days. In Fig. 9, some points show a large discrepancy between lidar and radiosonde. These outliers correspond to specific atmospheric conditions. Taking the example of the two circled points of Fig. 9, they correspond to the two highest points (at $4.5 \mathrm{~km}$ a.s.l.) of the same lidar profile on 9 June 2010 at midday. At this time, large relative humidity variations from the ground to 5-6 km were observed, with many structures. This is an example of a difficult measuring condition for both the radiosonde humidity sensor and the lidar, which might produce discrepancies.

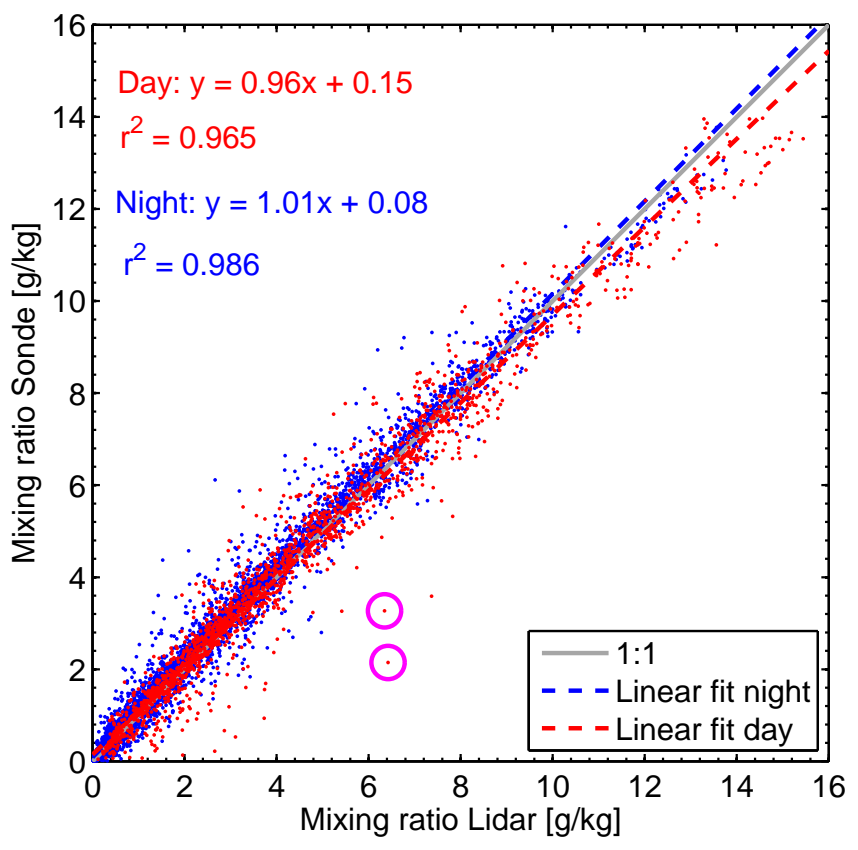

Fig. 9. Water vapor mixing ratio correlation plot between lidar and radiosondes for night (blue) and day (red) for all altitude levels (day: 2239 points, night: 6887 points). Magenta circled points are references for discussion in the paper. Only clear-sky days are considered. Period: 1 October 2009 to 30 September 2010.

\subsection{Integrated water vapor}

Integrated water vapor (IWV) has been calculated from lidar and radiosonde profiles. Theoretically, in order to calculate IWV from humidity profiles, the complete water vapor column up to the top of the atmosphere is necessary. In practice, however, because water vapor density decreases exponentially with height, calculations based only on tropospheric water vapor give a good IWV approximation. In this study, lidar IWV has been calculated only from lidar profiles reaching an altitude of at least $8 \mathrm{~km}$. The height of $8 \mathrm{~km}$ is a compromise between having enough profiles and a representative IWV. From the ground to $8 \mathrm{~km}$, about $99 \%$ of the total water vapor column is taken into account (calculation from radiosonde profiles, not shown). It also means that nights and mostly clear-sky conditions are selected. Radiosonde IWV is calculated from the whole radiosonde profiles. During the year under study, a total of 105 lidar profiles have been eligible for IWV calculation.

Lidar profiles do not start at ground level, but at several tens of meters above the instrument. Under normal conditions, the first point of measurement is at a height of $75 \mathrm{~m}$ above ground level. When calculating IWV, this lowermost layer is of importance since it contains a relatively large amount of water vapor. In this study, we used the reference 2 meter-height humidity measurements from the nearby SwissMetNet automatic weather station (Roulet et al., 2010), 


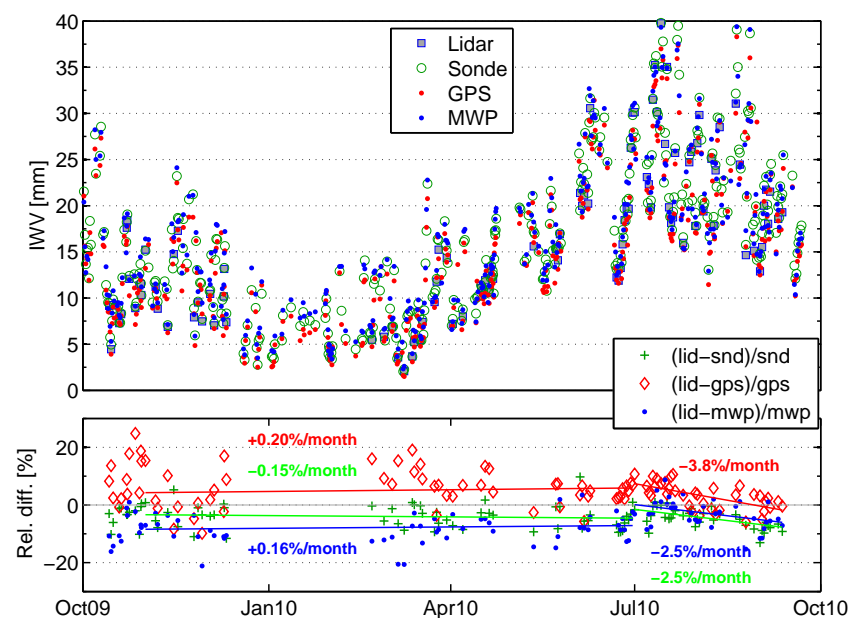

Fig. 10. Top panel: Integrated water vapor (IWV) time series above Payerne retrieved from radiosondes, GPS, microwave radiometer and lidar (for the lidar, only profiles reaching at least $8 \mathrm{~km}$ are used, which correspond mostly to clear-sky and night conditions). Bottom panel: Relative difference between lidar and radiosondes (green crosses), between lidar and GPS (red diamonds), and between lidar and microwave radiometer (blue dots). For example, $-10 \%$ means that lidar is $10 \%$ drier than reference. Generally, the lidar is drier than the radiosondes and more humid than GPS. Trends for the period November 2009 to June 2010 and for the period July to September 2010 have been added for information.

and extrapolate the value to the first point of the lidar profile. It is noted that humidity measurements at $2 \mathrm{~m}$ a.g.l. might be subject to local effects, such as evapotranspiration, leading to humidity overestimation.

Figure 10 shows the $1 \mathrm{yr}$ behavior of IWV over Payerne calculated from collocated lidar and radiosondes. IWV values from microwave radiometer and GPS measurements have been added to Fig. 10 for completeness, although it is noted that IWV from GPS measurements are not always reliable for lidar validation (Sussmann et al., 2009). In Payerne, IWV varies from a few millimeters in winter to about $40 \mathrm{~mm}$ in summer. Lidar shows a dry bias compared to the radiosonde (on average $4.2 \%$ ) and the microwave radiometer $(6.4 \%$ ), and a wet bias compared to the GPS (5.3\%). These results are also visible in the IWV correlation plots between lidar and radiosondes, GPS and microwave radiometer in Fig. 11. Of these differences, about $1 \%$ might be due to the fact that the lidar integrates only over a partial water vapor column. The correlation coefficients between the lidar and the other 3 instruments reach 0.99 . The observed IWV differences between the different instruments have been discussed in previous intercomparison work, e.g. in Martin et al. (2006) or Vogelmann et al. (2011).

\section{Discussion}

\subsection{Bias difference between night and day}

Mean yearly bias profiles during night and day (Figs. 7 and 8 , respectively) show different results. In the first few kilometers above the ground, lidar and radiosondes agree better during the day than during the night. The reason for this difference is not clearly established, although it is likely due to the effect of solar shortwave radiation. The measurement conditions during day and night are indeed very different.

Solar radiation has a strong influence on the lidar measurement. The strong solar background reduces the signal to noise ratio and hence increases the statistical uncertainty of the retrieved profile. Effects due to saturation of the water vapor channel during daytime are minimized using the analog signal instead of the photon counting signal. Given the strong background noise, the background correction becomes more important and introduces an additional uncertainty, especially at the top of the profile. On the other side, solar radiation has also some influence on the radiosonde's humidity sensor due to diffuse radiation into the ventilation channel. Dual flights using the SRS-C34 and the Vaisala RS92 showed that day measurements and night measurements have a different behavior (not shown). From these results, we cannot conclude which technique performs better during the day, since both lidar and radiosonde measure in difficult conditions. We consider the results obtained during night a better representation of the bias of the lidar with respect to the radiosonde.

\subsection{Humidity profile bias}

This study highlights the challenge of measuring humidity in the atmosphere. Conventional radiosonde humidity sensors are based on a resistor or a capacitor. The sensor's electrical properties change according to the relative humidity of the air surrounding the sensor. The retrieved humidity value is therefore based on the conversion between a humidity absorbing substrate and an electrical response. The retrieved profile is subject to many sources of errors. These include the uncertainty on the temperature at which the relative humidity is measured, and problems linked with sensor response time, extreme humidity conditions, rapid humidity changes, liquid water-to-ice transitions (SnowWhite), or individual sensor response. For a complete review of the different error sources on water vapor measurements from radiosondes, the reader is referred to WMO (2008) or Miloshevich et al. (2006) and references therein.

On the other hand, lidar systems use a totally different approach. The lidar's basic measurement principle is to measure backscattered light from molecules or particles as a function of time (distance, altitude). A Raman lidar or DIAL is measuring the intensity of inelastic backscatter from water molecules, or the specific absorption of (infrared) light 

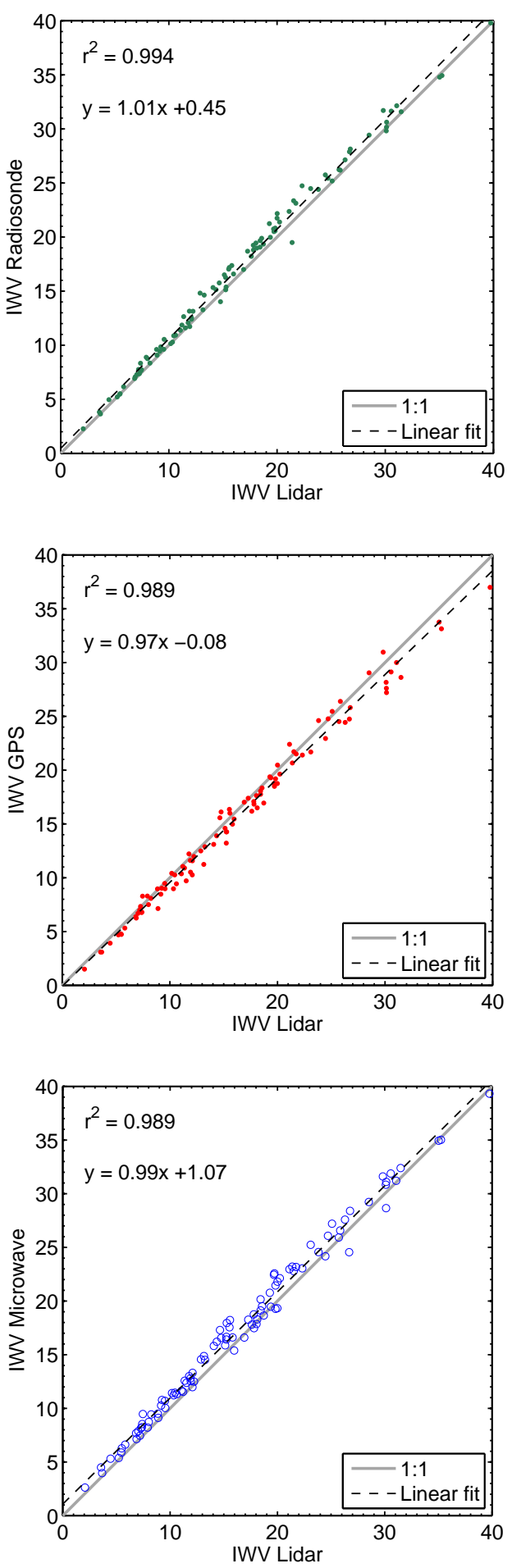

Fig. 11. Integrated water vapor (IWV) scatter plots between lidar and radiosondes (top), GPS (middle) and microwave radiometer (bottom). Linear fit are shown with dashed lines, while $1: 1$ guides are shown with solid grey lines. Period: 1 October 2009 to 30 September 2010 . Only lidar profiles reaching at least $8 \mathrm{~km}$ altitude are considered (100 profiles).
Table 3. Radiosonde and lidar measurement characteristics.

\begin{tabular}{lcc}
\hline & Radiosonde & Lidar \\
\hline Profile height & $>10 \mathrm{~km}$ & $\begin{array}{l}\text { 8-9 km (night) } \\
\text { 3-4 km (day) }\end{array}$ \\
Temporal sampling & $12 \mathrm{~h}$ & $0.5 \mathrm{~h}$ \\
Technology & Proven & Research \\
Sensor type & In situ & Remote sensing \\
Subject to weather/ & Weak & Strong \\
illumination & & \\
Reliability/robustness & High & Low \\
Running costs & High & Low \\
Acquisition & Manual & Automatic \\
\hline
\end{tabular}

by water molecules, respectively. The lidar thus overcomes most of the difficult measuring conditions. Problems related to the radiosonde sensor mentioned above become largely irrelevant in the lidar retrieval algorithm. Nonetheless, Raman lidar observations need to be initially referred to an absolute calibration value: the humidity profile has to be calibrated against a reference profile. In the present study, all statistical results are analyzed based on the lidar calibration of October 2009.

It is possible that the bias seen during the comparison (e.g. in Fig. 7) is related to the bias of the radiosonde. This would confirm the bias observed during the 2010 WMO intercomparison campaign (Nash et al., 2011). Likewise, in terms of integrated water vapor, lidar's underestimation visible in Fig. 11 (top) might also actually be an overestimation from the radiosonde. This IWV overestimation from the radiosonde was also underlined during the 2010 intercomparison campaign. Furthermore, this assumption is reinforced by the comparison between lidar and GPS (Fig. 11, middle), where both instruments are well correlated. Thus, although the long-term stability of the lidar is clearly more questionable than the stability of the sonde, a range of factors suggests that, for the year under study, the lidar underlines the already known bias of the radiosonde.

\subsection{System complementarity}

Lidar and radiosondes provide information that could be seen as redundant. Consequently, it is reasonable to ask whether both systems are needed on the same site. The example shown in Fig. 1 illustrates this point. Theoretically, a well-calibrated lidar could cover the water vapor information given by the radiosondes. In practice, however, both instruments suffer from clear limitations. A list of important inherent system parameters regarding radiosondes and lidar is given in Table 3. The main drawbacks for the lidar are the limited profile heights during daylight and cloudy days, and the measurement discontinuity due to either weather or technical problems. Discontinuity would be a problem, for example, for a model relying solely on the lidar for humidity 
and temperature profiles. Both height and continuous observations are guaranteed with radiosondes. On the other hand, the main drawback for radiosondes is the relatively low temporal resolution, which leaves a $12 \mathrm{~h}$ gap between two consecutive profiles. The lidar, with a profile every $30 \mathrm{~min}$, has the capability to fill this gap. Hence, lidar and radiosondes are in many ways complementary. Also, for the first time the lidar is providing real-time information on the humidity profile, which will be of prime importance in next-generation high-resolution numerical weather prediction models, and in particular in the field of rain forecast. Moreover, the lidar provides profiles averaged over time (here $30 \mathrm{~min}$ ) and over altitude layers, which is similar to what models require.

\section{Conclusions and outlook}

The water vapor profiles measured by the lidar were validated using a $1 \mathrm{yr}$ collocated radiosonde dataset. The water vapor mixing ratio agreement was within 3 percent up to $3 \mathrm{~km}$ during the day, and within 5 to 10 percent up to $8 \mathrm{~km}$ during the night. Relative humidity agreement was within 2 and 5 percent for day and night, respectively. The calculated integrated water vapor confirmed the quality of the measurement. Lidar compares well with radiosondes, microwave radiometer and GPS. Correlation plots show good results in the whole integrated water vapor content range from dry to wet (typically up to $40 \mathrm{~mm}$ IWV) atmospheric conditions. This study also showed that the system remained stable over 8 months, but nevertheless a calibration check every month has been introduced.

This analysis is based on a subset of approximately 200 lidar/sonde pairs. This represents about $2 \%$ of the 9046 lidar profiles. However, it is assumed that the results apply to the whole $30 \mathrm{~min}$ time resolution lidar dataset. This validation opens the door to the assimilation of lidar profiles into operational models such as Cosmo-2 (COnsortium for Small-scale MOdelling). Lidar data complement regular radiosonde data and give valuable information on the state of the atmosphere between two radiosonde launches. These data can be used to follow the evolution of humidity in the troposphere in near real time.

The next step concerning the development of the lidar is the validation of temperature profiles. When lidar temperature profiles from rotational Raman lidar operation become available, the calculation of relative humidity based only on lidar measurements becomes possible.

This study shows that lidar data are ready to be combined to different instruments such as radiosondes, microwave radiometer and GPS, in order to build temperature and humidity profiles up to the tropopause at a high temporal resolution.

Acknowledgements. This work was produced within the framework of COST action ES0702 "European Ground-Based Observations of Essential Variables for Climate and Operational Meteorology
EG-CLIMET". It is supported by the State Secretariat for Education, Research and Innovation SERI, and contributes to the project "Integration of remote sensing and radiosonde profiling systems: towards a reference for aerological profiling for weather and climate S(wiss)G-CLIMET".

Edited by: D. Feist

\section{References}

Apituley, A., Wilson, K., Potma, C., Volten, H., and de Graaf, M.: Performance assessment and application of CAELI - A highperformance Raman lidar for diurnal profiling of Water Vapour, Aerosols and Clouds, in: Proceedings of the 8th International Symposium on Tropospheric Profiling, edited by: Apituley, A., Russchenberg, H. W. J., and Monna, W. A. A., Delft, The Netherlands, October 2009, 2009.

Bleisch, R., Kämpfer, N., and Haefele, A.: Retrieval of tropospheric water vapour by using spectra of a $22 \mathrm{GHz}$ radiometer, Atmos. Meas. Tech., 4, 1891-1903, doi:10.5194/amt-4-1891-2011, 2011.

de Haan, S., Holleman, I., and Holtslag, A. A. M.: Real-Time Water Vapor Maps from a GPS Surface Network: Construction, Validation, and Applications, J. Appl. Meteorol. Clim., 48, 1302-1316, doi:10.1175/2008JAMC2024.1, 2008.

Dinoev, T.: Automated Raman lidar for day and night operational observation of tropospheric water vapor for meteorological applications, Ph.D. Thesis, Federal Institute of Technology EPFL, Lausanne, Switzerland, 2009.

Dinoev, T., Simeonov, V., Arshinov, Y., Bobrovnikov, S., Ristori, P., Calpini, B., Parlange, M., and van den Bergh, H.: Raman Lidar for Meteorological Observations, RALMO - Part 1: Instrument description, Atmos. Meas. Tech., 6, 1329-1346, doi:10.5194/amt-6-1329-2013, 2013.

Dionisi, D., Congeduti, F., Liberti, G. L., and Cardillo, F.: Calibration of a Multichannel Water Vapor Raman Lidar through Noncollocated Operational Soundings: Optimization and Characterization of Accuracy and Variability, J. Atmos. Ocean. Technol., 27, 108, doi:10.1175/2009JTECHA1327.1, 2010.

Duerr, B. and Philipona, R.: Automatic cloud amount detection by surface longwave downward radiation measurements, J. Geophys. Res., 109, D05201, doi:10.1029/2003JD004182, 2004.

Engelbart, D., Reichardt, J., Mattis, I., Wandinger, U., Klein, V., Meister, A., Hilber, B., and Jaenisch, V.: RAMSES - German meteorological service Raman lidar for atmospheric moisture measuring, in: Proceedings of the 23rd International Laser Radar Conference (ILRC), Nara, Japan , 24-28 July, 683-686, 2006.

Eumetnet: WMO FM94 (BUFR) Specification for GNSS Water Vapour Data, Tech. Rep. E-GVAP/METO/FMT/BUFR/001, EIG EUMETNET, 2009.

Ferrare, R., Turner, D., Clayton, M., Schmid, B., Redemann, J., Covert, D., Elleman, R., Ogren, J., Andrews, E., Goldsmith, J. E. M., and Jonsson, H.: Evaluation of daytime measurements of aerosols and water vapor made by an operational Raman lidar over the Southern Great Plains, J. Geophys. Res., 111, D05S08, doi:10.1029/2005JD005836, 2006.

Fujiwara, M., Shiotani, M., Hasebe, F., Vömel, H., Oltmans, S. J., Ruppert, P. W., Horinouchi, T., and Tsuda, T.: Performance of the Meteolabor "Snow White" chilled-mirror hygrometer in the 
tropical troposphere: comparisons with the Vaisala RS80 A/HHumicap sensors, J. Atmos. Ocean. Technol., 20, 1534-1542, doi:10.1175/1520-0426(2003)020;1534:POTMSW $\dot{i} 2.0 . C O ; 2$, 2003.

Goldsmith, J., Blair, F. H., Bisson, S. E., and Turner, D. D.: Turnkey Raman lidar for profiling atmospheric water vapor, clouds, and aerosols, Appl. Opt., 37, 4979-4990, 1998.

IPCC: Climate change 2007: the physical science basis. Contribution of working group I to the Fourth Assessment Report of the Intergovernmental Panel on Climate Change, Cambridge University Press, Cambridge, United Kingdom and New York, NY, USA, 2007.

Kämpfer, N. (Ed.): Monitoring Atmospheric Water Vapour, vol. 10 of ISSI Scientific Report, Springer NewYork Dordrecht Heidelberg London, doi:10.1007/978-1-4614-3909-7, 2013.

Leblanc, T., McDermid, I. S., and Aspey, R. A.: First-year operation of a new water vapor Raman lidar at the JPL Table Mountain Facility, California, J. Atmos. Ocean. Technol., 25, 1454-1462, doi:10.1175/2007JTECHA978.1, 2008.

Leblanc, T., Walsh, T. D., McDermid, I. S., Toon, G. C., Blavier, J.-F., Haines, B., Read, W. G., Herman, B., Fetzer, E., Sander, S., Pongetti, T., Whiteman, D. N., McGee, T. G., Twigg, L., Sumnicht, G., Venable, D., Calhoun, M., Dirisu, A., Hurst, D., Jordan, A., Hall, E., Miloshevich, L., Vömel, H., Straub, C., Kampfer, N., Nedoluha, G. E., Gomez, R. M., Holub, K., Gutman, S., Braun, J., Vanhove, T., Stiller, G., and Hauchecorne, A.: Measurements of Humidity in the Atmosphere and Validation Experiments (MOHAVE)-2009: overview of campaign operations and results, Atmos. Meas. Tech., 4, 2579-2605, doi:10.5194/amt-42579-2011, 2011.

Leblanc, T., McDermid, I. S., and Walsh, T. D.: Ground-based water vapor raman lidar measurements up to the upper troposphere and lower stratosphere for long-term monitoring, Atmos. Meas. Tech., 5, 17-36, doi:10.5194/amt-5-17-2012, 2012.

Löhnert, U., Kneifel, S., Battaglia, A., Hagen, M., Hirsch, L., and Crewell, S.: A Multisensor Approach Toward a Better Understanding of Snowfall Microphysics: The TOSCA Project, B. Am. Meteorol. Soc., 92, 613-628, doi:10.1175/2010BAMS2909.1, 2011.

Martin, L., Matzler, C., Hewison, T., and Ruffieux, D.: Intercomparison of integrated water vapour measurements, Meteorol. Z., 15, 57-64, doi:10.1127/0941-2948/2006/0098, 2006.

Miloshevich, L. M., Vömel, H., Whiteman, D. N., Lesht, B. M., Schmidlin, F. J., and Russo, F.: Absolute accuracy of water vapor measurements from six operational radiosonde types launched during AWEX-G and implications for AIRS validation, J. Geophys. Res., 111, 1-25, doi:10.1029/2005JD006083, 2006.

Nash, J., Oakley, T., Vömel, H., and Wei, L.: WMO intercomparison of high quality radiosonde systems, Yangjiang, China, 12 July-3 August 2010, Tech. Rep. 107, World Meteorological Organization, available at: http://www.wmo.int/pages/prog/www/ IMOP/publications/IOM-107_Yangjiang.pdf, wMO/TD-No. 1580, 2011.
Philipona, R., Levrat, G., Romanens, G., Jeannet, P., Ruffieux, D., and Calpini, B.: Transition from VIZ/Sippican to ROTRONIC - A new humidity sensor for the SWISS SRS 400 Radiosonde, Arbeitsberichte der MeteoSchweiz 229, MeteoSwiss, available at: http://www.meteoschweiz.admin.ch/web/de/forschung/ publikationen/alle_publikationen/abb_229.html, 2009.

Roulet, Y.-A., Landl, B., Félix, C., and Calpini, B.: Development and challenges in SwissMetNet, the new Swiss meteorological network, Presented at the TECO-2010 - WMO Technical Conference on Meteorological and Environmental Instruments and Methods of Observation, 2010.

RPG: Instrument Operation and Software Guide, Tech. Rep. RPGMWR-STD-SW, 01/01, Radiometer Physics GmbH, Meckenheim, Germany, 2011.

Schneider, M., Romero, P. M., Hase, F., Blumenstock, T., Cuevas, E., and Ramos, R.: Continuous quality assessment of atmospheric water vapour measurement techniques: FTIR, Cimel, MFRSR, GPS, and Vaisala RS92, Atmos. Meas. Tech., 3, 323338, doi:10.5194/amt-3-323-2010, 2010.

Seidel, D. J., Berger, F. H., Diamond, H. J., Dykema, J., Goodrich, D., Immler, F., Murray, W., Peterson, T., Siststerson, D., Somme, M., Thorne, P., Vömel, H., and Wang, J.: Reference upper-air observations for climate: rationale, progress, and plans, B. Am. Meteorol. Soc., 90, 361-369, doi:10.1175/2008BAMS2540.1, 2009.

Sussmann, R., Borsdorff, T., Rettinger, M., Camy-Peyret, C., Demoulin, P., Duchatelet, P., Mahieu, E., and Servais, C.: Technical Note: Harmonized retrieval of column-integrated atmospheric water vapor from the FTIR network - first examples for longterm records and station trends, Atmos. Chem. Phys., 9, 89878999, doi:10.5194/acp-9-8987-2009, 2009.

Vogelmann, H., Sussmann, R., Trickl, T., and Borsdorff, T.: Intercomparison of atmospheric water vapor soundings from the differential absorption lidar (DIAL) and the solar FTIR system on Mt. Zugspitze, Atmos. Meas. Tech., 4, 835-841, doi:10.5194/amt-4-835-2011, 2011.

Vömel, H., Fujiwara, M., Shiotani, M., Hasebe, F., Oltmans, S. J., and Barnes, J. E.: The behavior of the Snow White chilled-mirror hygrometer in extremely dry conditions, J. Atmos. Ocean. Technol., 20, 1560-1567, doi:10.1175/15200426(2003)020;1560:TBOTSW ¿2.0.CO;2, 2003.

Wirth, M., Fix, A., Ehret, G., Reichardt, R., Begbie, R., Engelbart, D., Vömel, H., Calpini, B., Romanens, G., Apituley, A., Wilson, K. M., Vogelmann, H., and Trickl, T.: Intercomparison of Airborne Water Vapour DIAL Measurements with Ground Based Remote Sensing and Radiosondes within the Framework of LUAMI 2008, in: Proceedings of the 8th International Symposium on Tropospheric Profiling, edited by: Apituley, A., Russchenberg, H. W. J., and Monna, W. A. A., Delft, The Netherlands, October 2009, 2009.

WMO: Guide to Meteorological Instruments and Methods of Observation. Part I. Measurement of upper-air pressure, temperature and humidity, Chap. 12, I.12-1-I.12-46, WMO-No. 8, World Meteorological Organization, Geneva, Switzerland, 2008. 